\title{
A IMPORTÂNCIA DO PLANEJAMENTO PARA O CUMPRIMENTO DE PRAZOS E REDUÇÃO DE CUSTOS EM PROJETOS NA ÁREA DE TI
}

\author{
Leandro Gustavo Schneider Neves ${ }^{1}$
}

\begin{abstract}
RESUMO
As empresas que efetuam planejamento com qualidade antes de iniciar a execução dos seus projetos têm como benefício maior resultado e satisfação dos seus clientes, porém, devido ao aumento da competitividade, muitas empresas reduzem o tempo de planejamento de um projeto com objetivo de colocá-lo mais rapidamente no mercado, ação que pode trazer aumentos de custos para a empresa e a insatisfação do cliente. Assim, o presente artigo procura por intermédio de uma pesquisa exploratória, traçar o perfil das empresas de Tecnologia da Informação (TI) que efetuam planejamento, além de tentar compreender as causas da não utilização de mais tempo para essa etapa.
\end{abstract}

Palavras-chave: Planejamento. Gerenciamento de Projeto. Custos e prazos.

1Especialista, e-mail: leandrogsn@sc.senai.br 


\section{INTRODUÇÃO}

Os anos 60 e 70, segundo Horwitch (1986) são considerados como "idade de ouro" no planejamento empresarial e industrial, neste tempo houve a proliferação de conceitos, de escolas de administração, consultoria, staffs de planejamento, que apresentavam a aceitação da teoria do planejamento estratégico. Houve o auge do planejamento e dos profissionais que trabalhavam na área industrial e, assim começou a ser inserido o planejamento em diversas áreas.

O emprego dos computadores e sistemas de informação pelas empresas marcaram os anos 70, com intuito de processar diversas tarefas simultaneamente com vários usuários.

Já nos anos 80 surgem os problemas de planejamento estratégico nas áreas de inovação tecnológica, no desenvolvimento de novos produtos e na entrada de novos mercados, principalmente o mercado americano e a entrada das empresas japonesas (HORWITCH, 1986).

O termo Tecnologia da Informação surge nos anos 80, com a demanda cada vez maior de dados e informações, sendo que a manipulação das informações tornou-se difícil de ser realizada manualmente, acarretando erros e desperdícios de tempo. Diante desse cenário surgem os programas de computadores responsáveis pelo gerenciamento de uma base de dados, chamados de Sistema de Gerenciamento de Banco de Dados (SGBD).

O presente artigo procura demonstrar a importância do planejamento para cumprimento de prazos e redução de custos em projetos na área de Tecnologia da Informação (TI).

O estudo realizado trata-se de uma pesquisa exploratória e o procedimento adotado é: entrevistas por meio de questionário. Sendo que os pesquisados são profissionais da área de $\mathrm{Tl}$ em diversas empresas.

Utilizou-se como base a fundamentação teórica dos seguintes autores: Vargas (2005), Kerzner (1995) e Sommerville (2007) para elucidar a relevância do tema.

Assim, é possível realizar um comparativo com a finalidade de demonstrar o valor do planejamento e do gerenciamento de projetos para as organizações.

Desta forma, divide-se a estrutura do estudo nos seguintes tópicos a seguir:

a) a problemática apresenta uma relação do ínfimo tempo para o planejamento, que acarretará no não cumprimento de prazos e no aumento de custos em projetos de área de Tl;

b) a descrição, análise dos dados e interpretação dos resultados da pesquisa aplicada aos profissionais de área de TI em diversos níveis e formação;

c) as considerações finais e a consolidação das informações apuradas. 


\title{
2 A PROBLEMÁTICA
}

O planejamento constitui-se importante para o cumprimento de prazos e redução de custos em projetos na área de TI. Com base nos relatos descritos procuram-se identificar, os fatores que determinam ou que contribuem na importância do planejamento. Sobre o tema, o autor esclarece:

\begin{abstract}
Os projetos atingem todos os níveis da organização. Eles podem envolver uma quantidade pequena de pessoas, ou milhares delas. Podem levar menos de um dia até vários anos. Os projetos muitas vezes extrapolam as fronteiras da organização, atingindo fornecedores, clientes, parceiros e governo, fazendo parte, na maioria das vezes, da estratégia de negócios da companhia. (VARGAS, 2005, p.5.)
\end{abstract}

Cabe lembrar a definição de planejamento, que significa antecipar-se aos problemas, ou resolvê-los quando acontecem, bem como tomar decisões com base em problemas anteriores.

Há uma constante preocupação de se entregar o produto que foi solicitado no prazo e sem o aumento de custo.

No Brasil, várias entidades públicas e privadas como, por exemplo, o SEBRAE Serviço de Apoio às Micro e Pequenas Empresas, divulgam enormes taxas de falências e, em muitas dessas empresas que encerraram suas atividades, os diagnósticos revelam a falta de planejamento como um fator preponderante para o fracasso. Talvez a falta da prática de planejamento nas pequenas e médias organizações brasileiras seja um problema cultural, onde ainda impera entre os empresários, em face da necessidade latente dessa prática, o velho “jeitinho brasileiro" de fazer as coisas (LIMA, DESCONCI e EHLERS, 2004, p.2).

Com base na citação supracitada, destaca-se que independente da empresa, e do seu porte, a falta da prática em fazer o planejamento e a cultura brasileira do "jeitinho", acarreta outro problema de planejamento.

Mesmo com a grande quantidade de benefícios gerados pelos projetos, a grande maioria deles falha, ou não atinge o resultado esperado. As principais falhas são decorrentes de inúmeros obstáculos naturais que, muitas vezes, estão fora do controle do gerente do projeto (VARGAS, 2005, p.12.).

Observa-se que mesmo com a prática do planejamento, ter-se-á problemas. Destaca-se ainda, a importância de planejar para reduzir os impactos negativos e prever possíveis desvios de projeto que geram perdas menores para a empresa. Com isso, tem-se que investir mais tempo na fase de planejamento de um projeto, que resulta em maior economia e redução de retrabalho, refletindo diretamente na sustentabilidade e nos resultados da empresa.

Considera-se três aspectos fundamentais para análise, são eles: performance, custo e tempo, características dos projetos e hierarquia dos sistemas. 
De acordo com Kerzner (1995) um projeto é definido como performance, custo e tempo, cada um dependente do outro, sob influência direta dos recursos que estão no centro do triângulo, como observa-se na figura 1. A substituição de um recurso por qualquer outro, acarreta nas relações de vinculo entre performance, custo e tempo. Com mais tempo de planejamento ter-se-ia impacto na performance, tempo e custo de um projeto.

Figura 1: Performance, custo e tempo

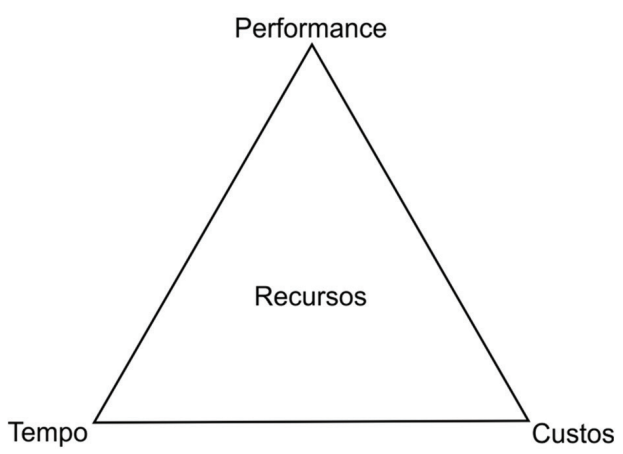

Fonte: Kerzner (1995, p.43)

Segundo Shtub, Bard e Globerson (1994) a relevância de performance, custo e tempo é composta pelo tipo de cada projeto, sendo que alguns projetos tem mais evidência a performance, outros custo ou tempo, conforme as características do projeto, apresentados na figura 2 a seguir:

Figura 2: Características dos projetos

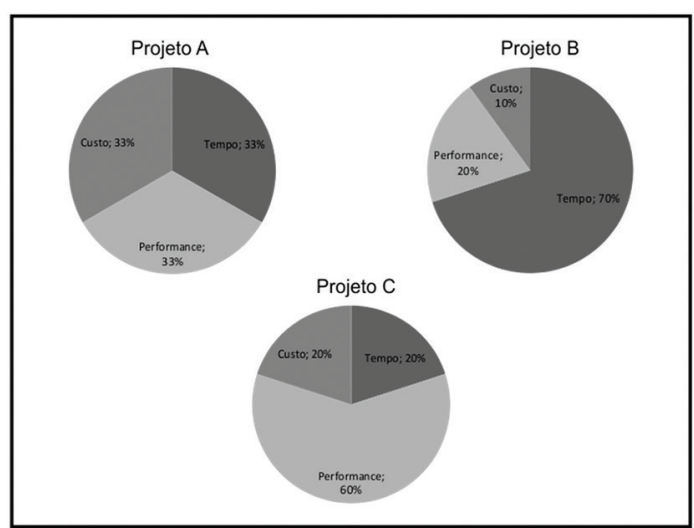

Fonte: Shtub, Bard e Globerson (1994, p.37).

Em continuação, destaca-se a figura 3 o modelo de hierarquia dos sistemas proposta por Kerzner (1995), sugere que não é indicado para empresas de TI, pois o gerente de projeto tem dificuldades de realizar a gestão por não fazer parte da lista de prioridades da empresa. 
Figura 3: Hierarquia dos sistemas

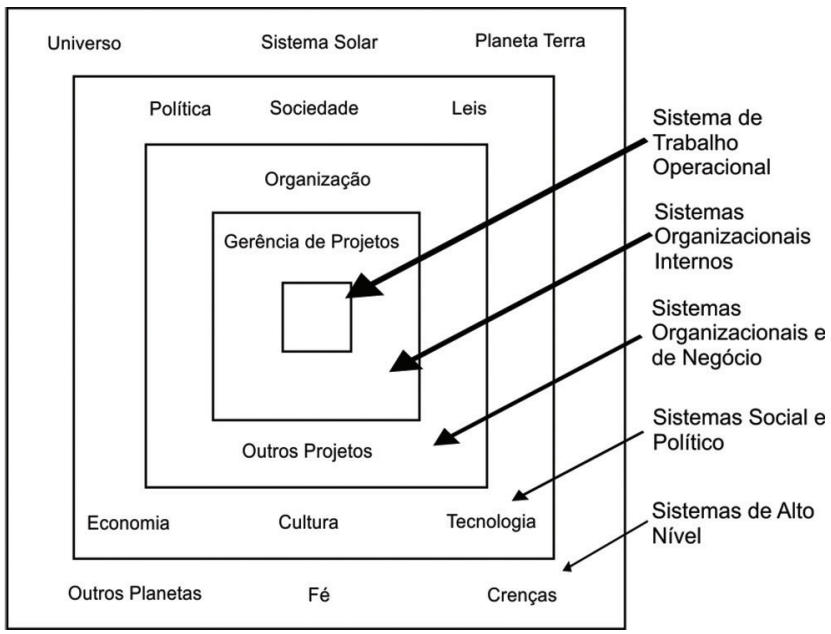

Fonte: Kerzner (1995, p.68)

Por fim, na figura 3 proposta por Kerzner (1995) a Gerência de Projetos é o ponto central da instituição, em seu entorno encontra-se Sistemas Organizacionais Internos, que seriam ferramentas para dar suporte a Gerência de Projetos, permeado por Sistemas organizacionais e Negócios, por sequência, Economia, Cultura, Tecnologia e Políticas da Empresa. Neste modelo destacam-se algumas características como: falta de disponibilidade e tempo para atuar em projetos, necessidade de consultorias para gerenciar os projetos e pouca disponibilidade para atuar e gerenciar projetos.

\section{OS PROCEDIMENTOS METODOLÓGICOS}

Para atender ao propósito do estudo, foi realizada uma pesquisa exploratória com diversas empresas, onde foram entrevistados vários profissionais de diferentes cargos da área de $\mathrm{TI}$, representando a visão desses profissionais quanto ao planejamento e gerenciamento de projetos, com objetivo de identificar a maturidade do planejamento sob olhar da direção de uma instituição e das pessoas que executam o projeto.

\subsection{Delineamentos da pesquisa}

A presente pesquisa caracteriza-se como qualitativa, por buscar identificar a percepção de planejamento da alta direção de empresas de TI e dos demais colaboradores que executam o planejamento. Além disso, é exploratória, por proporcionar maior familiaridade com o assunto. 
Neste sentido, a coleta de dados deu-se por meio virtual, utilizando-se de e-mail para convidar os profissionais da área de TI para acessar a ferramenta de questionário do Google doc's. "Nas pesquisas qualitativas, os dados são de natureza interpretativa e semântica, ou seja, nomeiam objetos reais ou abstratos de forma simbólica, através de atributos que Ihes dão significado." (GONÇALVES, 2004, p.59).

\subsection{Definições do universo e amostra da pesquisa}

Foi realizada pesquisa aberta por meio de questionário que pode ser encontrada no <https://docs.google.com/spreadsheet/viewform?formkey=dDlocTQzQXhoR25ZTXF wQ1RHS3BxUmc6MQ\#gid=0/>, utilizando-se como base o Livro "Gerenciamento de Programas e Projetos nas Organizações" (PRADO, 2004).

De acordo com a tabela 1 tem-se a noção do público que respondeu a amostra da pesquisa, que analisa a visão dos profissionais da área de TI em relação à cultura de planejamento e gerenciamento de projetos da empresa onde trabalham.

Com isso, observa-se que a maior parte da amostra é representada por programadores, em número de 13 pessoas exercendo este cargo.

Já o universo analisado representa a quantidade de e-mail enviados para cada profissional, ou seja, foram enviados 65 questionários para o cargo programador, 30 para o cargo administrativo, 15 para o cargo analista e 10 para o cargo de alta direção. E destes responderam ao questionário 13 do cargo programador, 5 do cargo administrativo, 4 do cargo analista e 3 do cargo alta direção. A partir disso, da quantidade de pessoas que responderam ao questionário, tem-se uma noção da amostra da pesquisa.

Tabela 1: Universo e amostra da pesquisa

\begin{tabular}{l|l|l}
\hline \multicolumn{3}{c}{ UNIVERSO E AMOSTRA DA PESQUISA } \\
\hline Fonte & Universo & Amostra \\
\hline Alta Direção & 10 & 3 \\
\hline Analistas & 15 & 4 \\
\hline Administrativo & 30 & 5 \\
\hline Programador & 65 & 13 \\
\hline
\end{tabular}

Fonte: Do autor 


\subsection{Técnica e instrumento de coleta de dados}

Foram enviados 120 e-mails convidando profissionais de área de TI para responderem o questionário desenvolvido, usando a ferramenta do Google doc's. Obteve-se desse total $20 \%$ de retorno desses profissionais. Como foram obtidas respostas de profissionais da área de $\mathrm{Tl}$ cujo cargo é extremamente importante para entendimento da pesquisa e muitas das respostas atenderam à proposta do estudo, foi considerado este número de respostas, realizada no período de março a abril de 2012.

As entrevistas por meio de questionários são instrumentos de coleta de dados que procuram atender aos objetivos específicos e ou categorias avaliadas apontados na tabela 2 a seguir:

Tabela 2: Descrição técnica e instrumento de coleta de dados

\begin{tabular}{l|l|l}
\hline Objetivos Específicos & Fonte & Instrumentos \\
\hline $\begin{array}{l}\text { a) Identificar cultura de planejamento e } \\
\text { gerência de projetos; }\end{array}$ & $\begin{array}{l}\text { Alta Direção, Analistas e } \\
\text { Programadores. }\end{array}$ & Questionário \\
\hline $\begin{array}{l}\text { b) Identificar nível de especialização em } \\
\text { gerência de projetos; }\end{array}$ & $\begin{array}{l}\text { Alta Direção, Analistas e } \\
\text { Programadores. }\end{array}$ & Questionário \\
\hline $\begin{array}{l}\text { c) Comparar a percepção da Alta Direção, } \\
\text { Analistas e Programadores, se o tempo } \\
\text { utilizado para planejamento dos projetos } \\
\text { foi adequada; }\end{array}$ & $\begin{array}{l}\text { Alta Direção, Analistas e } \\
\text { Programadores. }\end{array}$ & Questionário \\
\hline $\begin{array}{l}\text { d) Identificar alinhamento entre as áreas } \\
\text { da empresa; }\end{array}$ & $\begin{array}{l}\text { Alta Direção, Analistas e } \\
\text { Programadores. }\end{array}$ & Questionário \\
\hline $\begin{array}{l}\text { e) Identificar se a empresa cumpre com } \\
\text { os prazos dos projetos; }\end{array}$ & $\begin{array}{l}\text { Alta Direção, Analistas e } \\
\text { Programadores. }\end{array}$ & Questionário \\
\hline $\begin{array}{l}\text { f) Identificar sea empresa usa ferramentas } \\
\text { para gerenciamento de projetos. }\end{array}$ & $\begin{array}{l}\text { Alta Direção, Analistas e } \\
\text { Programadores. }\end{array}$ & Questionário \\
\hline
\end{tabular}

Fonte: Do autor 


\subsection{Limitações da pesquisa}

As análises apuradas e conclusões dete estudo refletem a uma amostra de $20 \%$ dos participantes. Estudos futuros sugerem ampliar o universo de pesquisados. Neste momento não é possível identificar os fatores de não participação dos demias convidados para a pesquia e ou inquerir quaisquer conclusões sobre os mesmos.

\section{DESCRIÇÃO DOS DADOS OBTIDOS, ANÁLISE DOS DADOS E INTERPRETAÇÃO DOS RESULTADOS}

A seguir apresentam-se alguns os itens avaliados e os resultados obtidos neste estudo.

Com relação ao GRAU ESCOLARIDADE - que trata da formação do profissional da área de TI, conforme a tabela 3.

Observa-se com os resultados colhidos que 32\% dos entrevistados possuem nível de escolaridade de pós-graduação. Isto demonstra que os profissionais da área de $\mathrm{Tl}$ estão cada vez mais especializados.

A continuação dos estudos em qualquer área de conhecimento é imprescindível, ainda mais na área de informática que se transforma e se inova a todo o momento.

Nota-se também um número considerável de profissionais com nível superior incompleto, que pode refletir na facilidade da inserção no mercado de trabalho na área de TI, ou ainda, em profissionais que se apaixonaram pela área e procuram conhecimento por meio da universidade. Ou ainda, outra possibilidade, que os profissionais que responderam ao questionário desistiram do curso de graduação ou são estudantes.

Pode-se sugerir a partir deste dado que, ou estes profissionais não estão trabalhando com gerenciamento de projetos, ou apenas são mecanismos de execução de projetos já elaborados, ou que por não possuírem este tipo de conhecimento apreendem as informações delegadas, por não terem vícios anteriores.

Com relação aos cargos de alta direção, observa-se uma, maior especialização na formação destes profissionais.

Ainda destaca-se, que $20 \%$ dos entrevistados têm nível superior completo, conforme índices apresentados na tabela 3, a seguir: 
Tabela 3: Grau de Escolaridade

\begin{tabular}{l|l|l}
\hline Escolaridade & Total & $\%$ \\
\hline Pós-Doutorado & 0 & 0 \\
\hline Doutores & 0 & 0 \\
\hline Mestrado & 4 & 16 \\
\hline Pós-Graduação & 8 & 32 \\
\hline Superior Completo & 5 & 20 \\
\hline Superior Incompleto & 6 & 24 \\
\hline 2o Grau Completo & 2 & 8 \\
\hline Total Fonte: Do autor & 25 \\
\hline \multicolumn{2}{|l|}{}
\end{tabular}

Com relação à EXPERIÊNCIA EM GERENCIAMENTO DE PROJETOS - que trata do tempo de vivência neste processo, conforme resultado apresentado na tabela 4.

Vislumbra-se que $40 \%$ dos profissionais que responderam ao questionário possuem somente de 1 a 3 anos de experiência em gerenciamento de projetos, o que pode acarretar ineficiência na execução dos projetos e afetar a qualidade do planejamento.

Além disso, essa ineficiência gera alto custo, demora na entrega dos produtos ou serviços, falha no relacionamento humano, entre outros fatores.

Primar por cursos em gerenciamento de projetos traz facilidade e comodidade para as empresas. A agilidade no atendimento é determinante, na encomenda ou no pedido, para após a concretização da venda do produto ou serviço e acarreta benefícios tanto para a empresa, como para os profissionais e para os clientes.

Analisa-se ainda que $24 \%$ dos entrevistados tem de 4 a 6 anos de experiência em gerenciamento de projetos, o que representa um avanço para a empresa que investe em material físico e humano.

Ao realizar bom desenvolvimento, execução e gerenciamento de projetos, reverte-se na venda de produtos aliada a uma política eficiente de projetos, que visa assegurar para as empresas e profissionais resultados promissores futuramente. 
Tabela 4: Experiência em Gerenciamento de Projetos

\begin{tabular}{l|l|l}
\hline Experiência & Total & $\%$ \\
\hline Menos de 1 ano & 5 & 20 \\
\hline $1-3$ anos & 10 & 40 \\
\hline $4-6$ anos & 6 & 24 \\
\hline $7-10$ anos & 1 & 4 \\
\hline $11-15$ anos & 1 & 4 \\
\hline $16-20$ anos & 2 & 8 \\
\hline Acima de 20 anos & 0 & 0 \\
\hline Total & 25 & \\
\hline
\end{tabular}

Fonte: Do autor

Com relação ao PORTE DA EMPRESA ONDE TRABALHA - que trata do número de funcionários, entre outras características, conforme resultado apresentado na tabela 5:

Obteve-se como resultado de que $44 \%$ dos entrevistados trabalham em empresas com mais de 500 funcionários.

Desta forma, empresas maiores a princípio deveriam investir mais na área de gerenciamento de projetos, devido a sua estrutura, diversidade de conhecimento humano e materiais.

As médias empresas também obtiveram uma representação significativa, com $24 \%$ dos entrevistados.

Nota-se que o porte da empresa é importante na análise da pesquisa, mas não é fundamental, eis que o conhecimento humano não é medido por quantidade, mas por qualidade.

Lembra-se que a maioria das falências das empresas tem como diagnóstico:

[...] a falta de planejamento como um fator preponderante para o fracasso. Talvez a falta da prática de planejamento nas pequenas e médias organizações brasileiras seja um problema cultural, onde ainda impera entre os empresários, em face da necessidade latente dessa prática, o velho "jeitinho brasileiro" de fazer as coisas. (LIMA, DESCONCl e EHLERS, 2004, p.2).

Neste sentido, o gerenciamento de projeto é uma ferramenta importante para facilitar o relacionamento humano e o desenvolvimento da empresa, mas deve ser trabalhado e estudado profundamente para se obter resultados positivos. 
Tabela 5: Porte da empresa onde trabalha

\begin{tabular}{l|l|l}
\hline Porte da empresa & Total & $\%$ \\
\hline Micro empresa (0 a 19 funcionários) & 4 & 16 \\
\hline Pequena empresa (20 a 99 funcionários) & 4 & 16 \\
\hline Média Empresa (100 a 499 funcionários) & 6 & 24 \\
\hline Grande Empresa (+ 500 funcionários) & 11 & 44 \\
\hline Total & 25 & \\
\hline
\end{tabular}

Fonte: Do autor

Se os pesquisados, com relação: se ESTUDOU ou se ESTUDA O PMBOK GUIDE, conforme resultado apresentado no gráfico 1.

Guia de boas práticas de gerenciamento de projetos (PMBOK) é um conjunto de conhecimentos gerenciado pela organização Project Management Institute (PMI). (UM GUIA...,2004).

O PMBOK é reconhecido como a mais importante bibliografia de gestão de projetos e procura contemplar os principais aspectos que podem ser abordados no gerenciamento de um projeto genérico. Entende-se que é um manual que descreve conhecimentos de gerenciamento de projetos, PMBOK tornou-se um padrão.

Observa-se que $72 \%$ dos entrevistados que trabalham em empresas com mais de 500 funcionários, confirmaram que estudaram ou estudam o guia de boas práticas de gerenciamento de projetos (PMBOK).

Com isso, é possível identificar uma preocupação dos entrevistados no estudo de gerenciamento de projetos. Fator relevante de uma ferramenta para desenvolver alternativas e projetos na área de $\mathrm{TI}$ visando o relacionamento com o cliente e o desenvolvimento interno do pessoal.

Cabe ainda lembrar, que tal resultado corrobora com o desenvolvimento do presente artigo, como uma tentativa de elucidar e trazer novas ferramentas para o gerenciamento de projetos para profissionais da área de TI.

Justifica-se por fim, que o gráfico 1 demonstra que as empresas com mais de 500 funcionários apresentam um resultado significativo. Desta forma, atende aos objetivos do presente artigo como, por exemplo, identificar cultura de planejamento e gerência de projetos e identificar nível de especialização em gerência de projetos. 
Gráfico 1: Empresas com mais de 500 funcionários \& relação de colaboradores que estudou ou estuda o PMBOK

\section{Você estudou/estuda o PMBOK} Guide?

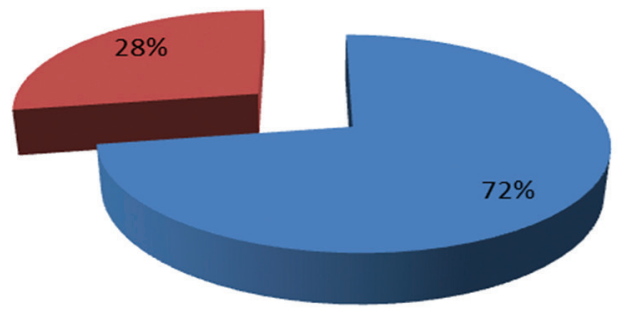

$$
\square \operatorname{sim}
$$

não

Fonte: Do autor

Com relação ao NÍVEL DA ALTA ADMINISTRAÇÃO, A ACEITAÇÃO DO ASSUNTO DE GERENCIAMENTO DE PROJETOS, conforme resultado apresentado na tabela 6.

Observa-se que independente de onde os entrevistados trabalham, constatou-se que $40 \%$ das pessoas que responderam ao questionário afirmam que o gerenciamento de projetos é bastante conhecido e aceito como uma boa prática de gerenciamento há, pelo menos, um ano (conforme item retirado do questionário, tabela 06, descrito a seguir). Pode-se ainda sugerir que a alta administração estimula o uso destes conhecimentos.

Destaca-se ainda que somente $12 \%$ das pessoas responderam ao questionário afirmando que a Alta direção possui algum receio quanto ao uso de práticas de gerenciamento de projetos.

Desta forma, entende-se que há estímulos partindo da alta direção para que seus profissionais estudem e utilizem a ferramenta gerenciamento de projetos.

O uso da ferramenta de gerenciamento de projetos está aliado às práticas normais da empresa, como uma forma de mitigar custos e aumentar o relacionamento humano dentro da empresa. Organização torna-se palavra chave. Eis que gerenciar tem como sinônimo organizar e com isso gerar lucro além de otimizar tempo. 
Tabela 6: No nível da alta administração, a aceitação do assunto gerenciamento de projetos

\begin{tabular}{l|c|c}
\hline Aceitação Gerenciamento de Projetos & Total & $\%$ \\
\hline $\begin{array}{l}\text { ussunto é bastante conhecido e aceito como } \\
\text { menos, um ano. A alta administração estimula }\end{array}$ & 10 & 40 \\
o uso destes conhecimentos. & & 28 \\
\hline $\begin{array}{l}\text { O assunto é razoavelmente conhecido e está } \\
\text { se iniciando o estímulo para o uso destes } \\
\text { conhecimentos. }\end{array}$ & 7 & 16 \\
\hline $\begin{array}{l}\text { O assunto é apenas conhecido. Não existe } \\
\text { nenhum estímulo formal para o uso destes } \\
\text { conhecimentos. }\end{array}$ & 4 & 12 \\
\hline $\begin{array}{l}\text { Existe algum receio da alta administração } \\
\text { quanto ao uso destes assuntos. }\end{array}$ & 4 & \\
\hline
\end{tabular}

Fonte: Do autor

Observa-se que mesmo com o gerenciamento de projetos presente há tantos anos, e diversas ferramentas disponíveis, encontra-se um grande número de falhas, que poderia ter seu impacto reduzido, caso se utilizasse um período maior para planejamento.

Neste contexto, com relação a, SE NA MAIORIA DAS VEZES O TEMPO UTILIZADO PARA PLANEJAMENTO DOS PROJETOS É ADEQUANDO observa-se na tabela 7 que $80 \%$ dos entrevistados afirmam que na maioria das vezes o tempo utilizado para planejamento dos projetos é inadequado.

O mercado de trabalho em si pressiona os profissionais para serem ágeis e em pouco tempo exerçam seus trabalhos. Não se pode esquecer a concorrência desleal, que se um profissional ou empresa não entrega um produto ou serviço em tempo adequado, mesmo sabendo ser impossível a sua execução, o cliente procura outro profissional ou empresa que atenda as suas necessidades.

No entanto, a redução do tempo de planejamento para o gerenciamento de projetos traz muitos transtornos. Um exemplo prático é partir diretamente para o desenvolvimento do projeto, o que acarreta no não cumprimento de prazos, serviços ou produtos incompletos, serviços/produtos com problemas, entre outros.

Com isso, além de vários transtornos descritos acima, a empresa ou profissional continua tendo como reflexo alto custo pela falta de gerenciamento no projeto, bem como a perda de credibilidade profissional e por último a insatisfação e perda do próprio cliente. 
Também, não se pode esquecer que $20 \%$ dos entrevistados respondeu ser na maioria das vezes o tempo para o planejamento de projetos adequado. Diante disso, pode-se observar que há empresas e profissionais que conseguem cumprir o planejamento de projeto, ocasionando a satisfação do cliente, o comprometimento da empresa ou profissional, além da maturidade de trabalhar, desenvolver e executar o planejamento e gerenciamento de projetos.

Tabela 7: Tempo utilizado para planejamento dos projetos, se é adequado

\begin{tabular}{l|l|l}
\hline $\begin{array}{c}\text { Tempo utilizado para } \\
\text { planejamento é adequado? }\end{array}$ & Total & $\%$ \\
\hline Sim & 5 & 20 \\
\hline Não & 20 & 80 \\
\hline
\end{tabular}

Fonte: Do autor

Nota-se que no âmbito de alta direção o tempo utilizado para planejamento é adequado, conforme tabela 8 . Observa-se que $66,66 \%$ dos diretores das empresas entrevistadas responderam que sim, os demais colaboradores afirmam que o tempo utilizado para planejamento é adequado, com resultado de 16,63\%.

Lembre-se, que a amostra contem 25 entrevistados e somente 5 destes concordam que o tempo utilizado para o planejamento é adequado.

Diante disto, denota-se que para a alta direção de grandes empresas o tempo para o planejamento do projeto não representa nenhum empecilho, pois normalmente estes dirigentes não têm ciência do tempo disponibilizado para a realização de cada etapa do projeto, e sim, a perspectiva de lucro final de cada projeto.

Diferentemente é a análise em relação às empresas de pequeno e médio porte, em que há envolvimento pessoal dos profissionais em cada etapa de execução dos projetos, e muitas vezes a alta direção tem conhecimento técnico do produto ou serviço a ser desenvolvido, o que acarreta na total ciência do tempo adequado para o planejamento do projeto.

Por fim, essas análises sugerem possíveis interpretações do questionário aplicado aos entrevistados. 
Tabela 8: Relação Alta Direção e demais colaboradores para planejamento adequado

\begin{tabular}{l|l|l}
\hline $\begin{array}{l}\text { Tempo utilizado para } \\
\text { planejamento é adequado? }\end{array}$ & $\begin{array}{l}\text { Total } \\
\text { Resposta Sim }\end{array}$ & $\%$ \\
\hline Alta Direção & 2 & 66,66 \\
\hline Demais colaboradores & 3 & 16,63 \\
\hline
\end{tabular}

Fonte: Do autor

Após a descrição dos dados coletados na pesquisa de campo, chegam-se as considerações finais, tecendo um olhar sobre a problemática apresentada no presente artigo.

\section{CONSIDERAÇÕES FINAIS}

Ao analisar os dados obtidos pela referida pesquisa, pode-se concluir que as empresas e os profissionais realizam planejamento. No entanto, devido à necessidade de rápida execução e redução de custos acabam partindo para o desenvolvimento e explorando pouca essa fase tão importante de um projeto - o planejamento. Devido a isso, uma série de problemas surge tanto para a empresa de TI quanto para o cliente.

Segundo Pinto ([2010?]) todo projeto tem o não atraso como característica marcante, todo projeto tem uma característica principal: alguns são prazos, outros são custos, porém em nenhum momento pode se descuidar da qualidade.

Para as empresas de TI a falta de planejamento acarreta vários problemas, dentre estes, pode-se citar: o retrabalho, a insatisfação dos profissionais desenvolvedores, o não cumprimento do prazo de entrega, a falta de comunicação entre a equipe de desenvolvedores ou direção e ou gerência, divergência no cronograma, riscos, custos altos, problemas na execução e ou implantação (Vargas, 2005).

Cabe ainda lembrar, que a empresa ou profissional pode ter como resultado da falta de planejamento a perda de credibilidade profissional, bem como a insatisfação e perda do próprio cliente.

Como forma de mitigar estes problemas, conclui-se que se as empresas devem utilizar o planejamento a seu favor e assim, com a finalidade de assegurar a excelência na qualidade: 
a) uma sequência clara e lógica de eventos;

b) um respeito o ciclo de vida (início, meio e fim) do planejamento;

c) estabelecer objetivos claros e bem definidos;

d) definir equipes de colaboradores preparados para executar tais responsabilidades;

e) ter clara uma previsão de valores de investimentos nos prazos, nos custos envolvidos, na equipe disponível para tal projeto, nos materiais e nos equipamentos necessários para a execução dos trabalhos.

Esse conjunto de fatores reflete em mais competitividade, com redução de custos e redução de ações corretivas durante todo o processo de desenvolvimento do projeto, bem como redução de conflitos entre os envolvidos.

Isso tudo se evidencia de forma clara quando se analisa os dados colhidos na pesquisa realizada com profissionais da área de $\mathrm{TI}$, que tem como ponto mais distante entre alta direção e analistas, a percepção mais apurada do nível de detalhamento do planejamento, antes do início da execução do projeto. A grande divergência se dá na percepção da alta direção, pois na visão desta a empresa se prepara e planeja os projetos de forma adequada, estimando tempo e pessoas.

Nota-se ainda a preocupação da alta direção em possibilitar a cultura de gerenciamento de projetos, por meio de investimentos em treinamento e incentivos aos colaboradores, porém sugere-se ampliar a sinergia entre a alta direção e demais setores das empresas.

No entanto, observa-se que para os analistas e programadores o fator tempo e apoio da alta direção impactam mais para que se tenha um planejamento mais assertivo. No cotidiano são estes profissionais que planejam, desenvolvem, gerenciam e executam os projetos. Cabe salientar que a falta de comunicação e apoio entre os diferentes níveis hierárquicos numa mesma empresa, independente do porte desta, é o fator determinante que causa falhas no gerenciamento de projetos.

Diante disso, sugere-se como proposta de solução deste problema, o treinamento e desenvolvimento para todos os profissionais envolvidos na temática de Gerenciamento de Projetos. Também a preparação para o cumprimento de metas nos projetos, o estímulo da alta direção para a continuação aos estudos e ou especializações, com a finalidade de se desenvolver melhor os projetos e as pessoas da empresa. Neste cenário inclui-se além da boa vontade e um esforço para mergulhar nos estudos voltados para planejamento na área de TI, objeto deste estudo e que merecem reflexões e continuidade de estudos futuros. 


\title{
THE IMPORTANCE OF PLANNING TO MEET DEADLINES AND TO REDUCE COSTS IN PROJECTS IN THE AREA OF IT
}

\begin{abstract}
Companies that perform quality planning before starting the execution of their projects have as benefit better results and customer satisfaction, however, due to the increase of competitivity many companies reduce the time of planning of a project aiming to launch it more rapidly on the market, a practice that can introduce an increase in the costs for the company and dissatisfaction of the customer. Therefore this article attempts through an exploratory research, to provide a profile of the companies of information technology (IT) that perform planning, in addition to try to understand the causes of not using more time for this step.
\end{abstract}

Keywords: Planning. Project Management. Costs and deadlines.

\section{REFERÊNCIAS}

GONÇALVES, Carlos Alberto; MEIRELLES, Anthero de Moraes. Projetos e relatórios de pesquisa em administração . São Paulo: Atlas, 2004.

HORWITCH, Mel. A estratégia empresarial. Administração de empresas. São Paulo: Nova Cultura, 1986.

KERZNER, Harold. Project Management: A systems aproach to planning scheduling and controlling. 5.ed. New York: Van Nostrand Reinhold, 1995.

LIMA, Sidarta Ruthes; DESCONCI, Tiago; EHLERS, Eduardo da Pieva . Pesquisa Quantitativa Política dos Negócios e Economia de Empresas. In: SEMINÁRIOS EM ADMINISTRAÇÃO, 7., 2004,São Paulo. Anais..., São Paulo: FEA/USP, 2004. Disponível em: <http://www.ead.fea.usp.br/semead/7semead >. Acesso em: 20 mar. 2012. 
PINTO, Americo. A cultura brasileira "de jeitinho" pode prejudicar planejamento. Entrevista concedida para Beatriz Leal assessoria de comunicação do CONFEA no Fórum nacional de benchmarking em gerenciamento de projetos. [2010?]. Disponível em: <http://www.confea.org.br/cgi/cgilua.exe/sys/start.htm?infoid=9964\&sid=1219>. Acesso em: 20 mar. 2012.

PRADO, Darci. Gerenciamento de Programas e Projetos nas Organizações. 3. ed. São Paulo: INDG-TECS, 2004.

UM GUIA do conjunto de conhecimentos em gerenciamento de projetos: guia PMBOK. 4. ed. Newtown Square, PA: Project Management Institute, c2008. xxvi, 459 p. ISBN 9781933890708.

SHTUB, Avraham; BARD, Jonathan F.;GLOBERSON, Shlomo. Project Management: engineering, technology and implementation. New Jersey: Prentice Hall, 1994.

SOMMERVILLE, Ian. Engenharia de Software. 8. ed. São Paulo: Pearson Addison Wesley, 2007.

VARGAS, Ricardo Viana. Gerenciamento de Projetos: estabelecendo diferenciais competitivos. 6. ed. Rio de Janeiro: Brasport. 2005.

\section{BIBLIOGRAFIAS}

FOINA, Paulo Rogério. Tecnologia de informação: planejamento e gestão. São Paulo: Atlas, 2001.

LEWIS, James P. Project Planning, Scheduling \& Control. Chicago: Irwin Professional Publishing, 1995.

ORTH, Afonso Inácio; PRIKLADNICKI, Rafael. Planejamento e gerência de projetos. Porto Alegre: EDIPUCRS, 2009.

SAMARANI, P. R. de M. Um modelo de implementação do Capability Maturity Model Integration nível 2. 2005. 135 f. Dissertação (Mestrado em Ciência da Computação) Universidade Federal do Rio Grande do Sul, Porto Alegre, 2005. 


\section{SOBRE O AUTOR}

\begin{tabular}{|l||l||}
\hline $\begin{array}{l}|l| \mid \\
\text { Leandro Gustavo } \\
\text { Schneider Neves }\end{array}$ & $\begin{array}{l}\text { Graduado em Web Design e Programação pela Universidade do Sul de } \\
\text { Santa Catarina (UNISUL), também em Engenharia de Computação pela } \\
\text { Universidade do Vale do Itajaí (UNIVALI), especialista em Gerência de Projetos } \\
\text { de Tecnologia da Informação pela Universidade do Sul de Santa Catarina } \\
\text { (UNISUL), técnico em Edificaçães pelo Instituto Federal de Educação, Ciência } \\
\text { e Tecnologia de Santa Catarina. Sócio fundador empresa de Tecnologia da } \\
\text { Informação Chipmaster Informática. Atuou como docente e coordenador } \\
\text { dos cursos de Manutenção e Suporte em Informática e Programação de } \\
\text { Computadores do SENAI/SC em São José. Foi coordenador do Núcleo de de } \\
\text { Informática do SENAI/SC em São José. Atualmente é Coordenador da AT- } \\
\text { Mecanismos de Inovação do SENAI/SC Direção Regional. }\end{array}$ \\
\hline
\end{tabular}

